\author{
Norma Fimbres Durazo* \\ Guadalupe Ortega Villa**
}

\title{
INMIGRACIÓN Y MOVILIDAD LABORAL DE TRABAJADORES MEXICANOS RESIDENTES LEGALES EN UNA CIUDAD FRONTERIZA DE ESTADOS UNIDOS: CALÉXICO, CALIFORNIA
}

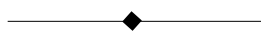

\section{RESUMEN}

A quí sedescribela movilidad laboral deun grupo detrabajadores migrantes mexicanos residentes legales queviven demanera permanenteen la ciudad de Caléxico, California, Estados Unidos. Esta ciudad desdeprincipios del siglo XX seha caracterizado por ser un asentamiento deinmigrantes dediferentes nacional idades, deellas sobresaleel grupo de inmigrantesmexicanosquedeformalegal, o indocumentada, han llegado atrabajar demanera temporal o permanente. En estetrabajo sepresentan, demanera general, tanto las causas quehistóricamenteoriginaron la inmigración detrabajadores mexicanos a esta localidad como su participación en el mercado laboral, con el objetivo deaproximarnosal estudio de lamovilidad laboral del trabajador inmigranteeidentificar al gunosfactoresqueintervinieron para quesellevaraacabo.

\section{A B STRACT}

This paper describes thelabor mobility of a group of M exican migrant workers that are permanent legal residents in thecity of Caléxico, Ca. USA. Sincethebeginnings of the XX century, this city has been a settlement of immigrants from different countries, among them stands out the Mexican immigrant group that, legally or illegally, has arrived to work temporal or permanently. In order to haveand approach to the study of the labor milility of the immigrant workers and identify some situations that madeit possible, this paper presents an overview of thehistoricevents that favored the immigration of Mexican workers to this city as well as their participation in the labor market.

\footnotetext{
* InVestigadora del instituto de INVESTIGACIONES SOCIALES DE LA uABC. Correo electrónico: nfimbres@faro.ens.uabc.mx

** INVESTIGADORA DEL INSTITUTO DE INVESTIGACIONES SOCIALES DE LA UABC. Correo electrónico: gortega@faro.ens.uabc.mx
} 


\section{INTRODUCCIÓN}

Aquí se describe la movilidad laboral de un grupo de trabajadores migrantes mexicanos residentes legales que viven de manera permanenteen la ciudad deCaléxico, Cal ifornia, Estados Unidos. Esta ciudad desde principios del siglo XX se ha caracterizado por ser un asentamiento de inmigrantes de diferentes nacionalidades, de ellas sobresale el grupo de inmigrantes mexicanos que de forma legal, o indocumentada, han llegado a trabajar de manera temporal o permanente. La ciudad deCaléxico (ver figura 1), es una delasciudades que conforman el Condado Imperial, quegeográficamenteseencuentra localizado en el extremo sur del estado deCalifornia, justo en los límites delafrontera mexicana que colinda con el municipio de M exicali, B. C., M éxico. La inmigración de mexicanos a esta región ha sido constante durante casi los últimos cien años, esta movilización de personas del sur de México a los Estados Unidos ha traído como consecuencia que Caléxico sedistinga por ser la ciudad fronteriza del sur delos Estados Unidos con mayor número de habitantes de origen mexicano (U.S. Bureau of the Census, Census of Population, 1990).

En este trabajo se presentan, de manera general, tanto las causas quehistóricamenteoriginaron la inmigración detrabajadoresmexicanos a esta localidad como su participación en el mercado laboral, con el objetivo de aproximarnos al estudio de la movilidad laboral del trabajador inmigrantee identificar al gunos factores queintervinieron para que se llevara a cabo dicha movilidad laboral. Para ello, en el primer apartado se hace una breve referencia a los conceptos de migración y movilidad quedan soportea lo aquí escrito. En el segundo apartado se describe la historia del poblamiento de la ciudad de Caléxico, Ca. y el papel quela fuerza detrabajo mexicana ha jugado en ese proceso. A partir del tercero se reportan los resultados de una investigación llevada a cabo entre los mexicanos residentes legales en esa ciudad. En este apartado se describen las características sociodemográficas, los cambios ocupacionales entre el último trabajo en México, el primero en Estados Unidos y el que realizaban al momento deser entrevistados, así como al gunos otros indicadores que pueden influir en la movilidad laboral de estegrupo de migrantes. 
FIGURA 1. Ubicación geográfica de las ciudades que integran el Condado Imperial, CA.

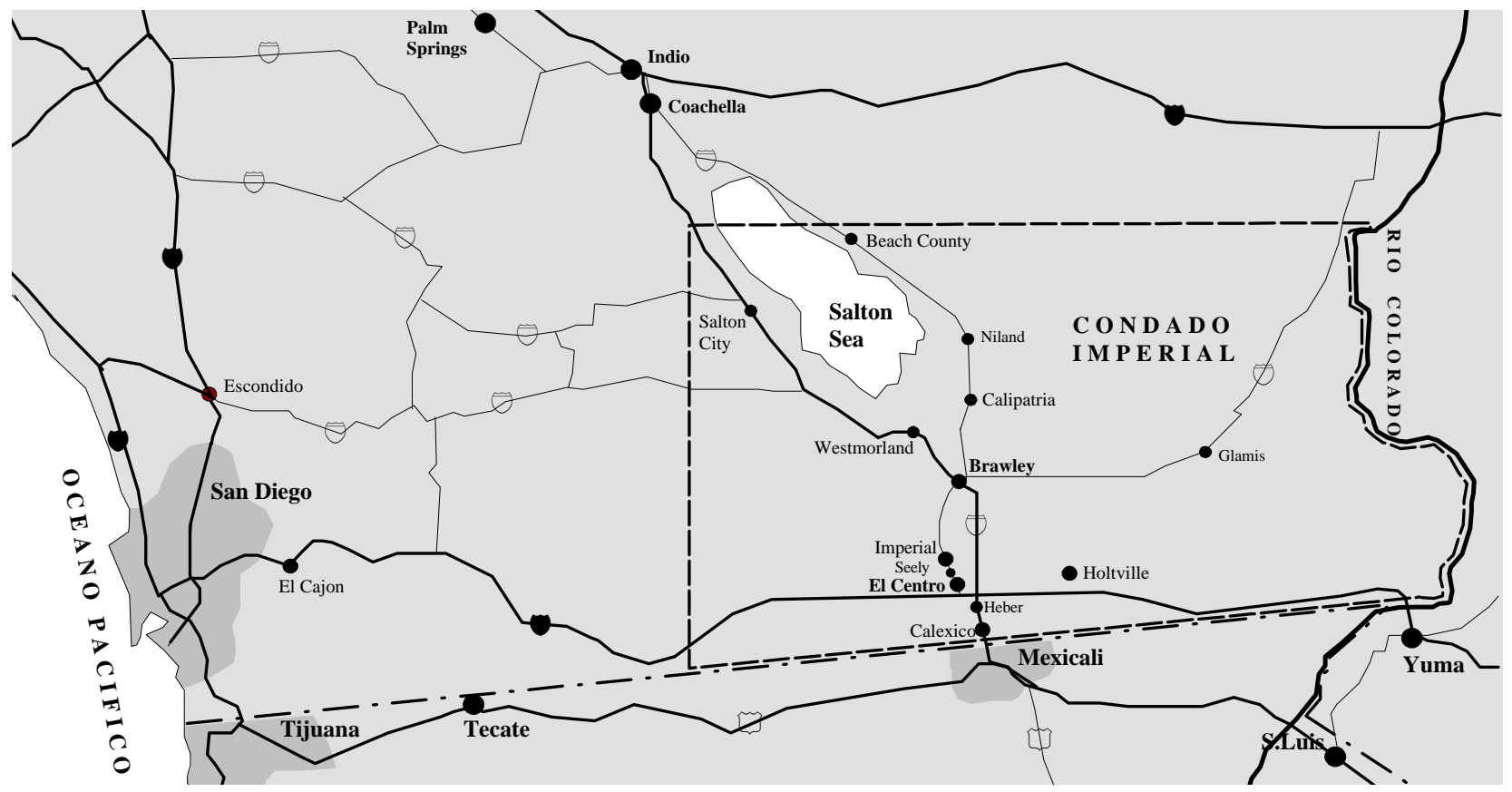

Fuente: Elaborado por Djamel Toudert, 2000. 
Los datos que se muestran en el tercer apartado son algunos resultados obtenidos del proyecto de investigación denominado "inmigración e integración de los inmigrantes mexicanos residentes legales en Caléxico, California", que implicó la aplicación de una encuesta que condujo a la entrevista de 407 mexicanos residentes legal es en esa ciudad durante $1995 .{ }^{1}$ Debido a queuno delos principales objetivos del proyecto era estudiar la movilidad laboral, la población objetivo, y por tanto la composición de la muestra, se definió como el grupo de personas que: a) fueran mexicanos de nacimiento; b) fueran residentes legales (con documentos para poder residir y trabajar en Estados Unidos); c) tuvieran una edad de 18 años o más y d) no hubieran obtenido la ciudadanía norteamericana, es decir, continuaran siendo ciudadanos mexicanos.

\section{MIGRACIÓN Y MOVILIDAD}

Se considera que la migración es reflejo del cambio socioeconómico que busca el migrante, ya que, en la mayoría de los casos, toma la decisión de migrar para mejorar las condiciones de vida. Así, "el individuo o la familia migran para aumentar su capital humano, esto es, aumentar su habilidad para generar un flujo de ingresos durante su vida como resul tado deesta decisión. En otras palabras, un individuo cambia delugar deresidenciasi considera quelos beneficios excederán los costos" (Clark, 1986: 66-67).

El movimiento migratorio puedeconsiderarse como un mecanismo de adecuación de la mano de obra a los requerimientos del mercado laboral, esto es: la relocalización de los trabajadores de las áreas o sectores de poca oferta de trabajo hacia otras áreas donde exista una mayor demanda laboral, o bien, el desplazamiento dezonas desalarios bajos a otras dealtos niveles sal ariales.

${ }^{1}$ La encuesta sellevó a cabo en los hogares de los inmigrantes y fue posi ble gracias al apoyo delas autoridades y alumnos delaUniversidad Estatal deSan Diego (SDSU), Campus Caléxico. 
La migración, como lo apunta Gaudemar, puede implicar varias formas de movilidad, dependiendo del interés particular del análisis. Si bien se pueden observar los patrones de desplazamiento territorial de la población, "también abarca sus homólogos sectoriales o profesionales. En todo caso, setrata deun desplazamiento deuna esfera a otra ..." (Gaudemar; 1976:14). Por ello, aquí consideramos que los cambios ocupacional es de los trabajadores inmigrantes son indicador dealgún tipo de movilidad laboral.

La movilidad laboral se puede presentar en dos modalidades: horizontal y vertical. La movilidad horizontal se presenta cuando el trabajador cambia de empleo y pasa a desempeñar otra actividad sin quese presente un cambio sectorial, en el sentido dequeel trabajador sigue en un puesto igual o similar. Por su parte, la movilidad vertical es aquella que implica un cambio de jerarquía en el puesto o posición en el trabajo, que puede presentarse dentro del mismo sector o simultáneamentecon una transferencia sectorial (Cuamea Velázquez, 1991:8).

En esta perspectiva, el concepto de movilidad laboral permite anal izar los diversos ámbitos en los que se ha desplazado la fuerza de trabajo de los inmigrantes, que, al tratarse de una inmigración internacional, debe tomar en cuenta las actividades realizadas tanto en el país de origen como las que han realizado en el de destino.

\section{CALÉXICO: CIUDAD DE ATRACCIÓN PARA LA INMIGRACIÓN MEXICANA}

La inmigración demexicanos en Estados Unidos hasido consecuencia de factores históricos de México y Estados Unidos y de las desigualdades económicas entre ambos países que se manifiestan en la expulsión y atracción de la mano de obra, México como país expulsor de población que emigra en busca de mejores condiciones de vida y Estados Unidos, dadas sus características económicas, como país de atracción queofreceal inmigrantela posibilidad deencontrar un trabajo mejor remunerado quele permita lograr mejorar su condición devida.

Desde principio del siglo XX se propició la inmigración mexicana en los estados del sur deEstados Unidos, debido a la entonces reciente integración económica delos estados del suroesteal desarrollo del país. 
Ello estimuló y fomentó la inmigración masiva de trabajadores mexicanos, primero debido al desarrollo de la red de transporte y comunicaciones por ferrocarril y, posteriormente, a la extracción de minerales y a la producción agrícola. Como consecuencia de la centralización y concentración de capitales en el sur del país, surgió una de las regiones agrícol as más productivas en el sur de Cal ifornia: el Valle Imperial, que años más tarde se convertiría en lo que hoy se conoce como el Condado Imperial.

En esos años, esta región seencontraba prácticamente deshabitada; su poblamiento y desarrollo se debió a la corriente migratoria procedente de diferentes estados del norte y del este de la Unión A mericana. Esta corriente migratoria fue propiciada por la Cal ifornia Development Co. (Compañía para el Desarrollo deCal ifornia), empresa encargada del desarrollo económico de la región que ofreció a inmigrantes y nativos la posibilidad de adquirir tierras para cultivo (Estrella, 1982: 8-10). Así, los asentamientos ubicados en el Valle Imperial son en gran medida el resultado dela movilización depersonas del norte de Estados Unidos hacia la frontera sur y de la inmigración de población del sur de México que se dirigió a la frontera norte y al sur de los Estados Unidos.

EI Valle Imperial seconvirtió en una región deatracción tanto para la fuerza de trabajo mexicana como para la población einversionistas norteamericanos. Este fenómeno ha sido una constante a lo largo del siglo XX, lo que puedeconsiderarsecomo un fenómeno relativamente singular, ya quedecientos defronteras quehay en el mundo, en pocas se han desarrol lado ciudades contiguas en ambos lados dela frontera (A legría, 1992:15), como es el caso de la ciudad de Mexicali, B. C. (en México) y la de Caléxico, $\mathrm{Ca}$. (en Estados Unidos), que se encuentran adyacentes a la línea fronteriza.

\section{O RIGEN Y CRECIMIENTO DE LA POBLACIÓN DE LA CIUDAD DE CALÉXICO}

Laciudad deCaléxico tienesu antecedenteen 1901, cuando la California Development Co. estableció su campamento y oficinas central es cerca de la frontera internacional entre California y Baja California, localización que permitía tener un mayor control sobrelos trabajos de 
irrigación que se estaban realizando en las zonas de cultivo en ambos lados de la frontera. A partir de ese momento Caléxico ha estado habitado ininterrumpidamente y se ha caracterizado por tener altas tasas decrecimiento depoblación, tanto natural como migrante. En el año de 1903 el área de Caléxico fuedividida y lotificada, surgiendo así lo quees el actual asentamiento urbano (Estrella, 1982:11). A partir de esos años se hizo presente la inmigración de mexicanos procedentes de distintos lugares de la república mexicana mismos que se incorporaron a las labores agrícolas. Esta corriente detrabajadores mexicanos ha sido constante durante todo el siglo XX y al gunos de ellos se han establecido como residentes permanentes en esta local idad.

Simultáneamente, del lado mexicano de la frontera se creó el asentamiento de la ciudad de Mexicali, B. C., con el paso del tiempo, Mexicali creció a un ritmo más acelerado que su gemela del lado norteamericano; sin embargo, ambas aumentaron su volumen poblacional como consecuencia de las corrientes migratorias provenientes del interior de México.

Uno de los acontecimientos que dio auge a Caléxico y le brindó la posibilidad de diversificar su estructura económica se presentó en la década delos treinta, cuando el gobierno federal mexicano implantó el régimen dezona libreen el entonces Territorio N ortedeBaja Cal ifornia, como una al ternativa para garantizar el abasto a la población mexicana radicada en la franja fronteriza y, en consecuencia, el asentamiento permanente. Esto condujo a quelas ciudades del sur deEstados Unidos, sobre todo aquellas ubicadas junto a la línea fronteriza, se convirtieran en abastecedoras de mercancías, bienes de consumo y servicios a la población fronteriza del lado mexicano (Esparza, 1983:588). Caléxico no fue la excepción, y todavía a mediados de la década de los setenta erael principal centro deabasto delos mexicalenses, lo quelepermitió añadir a su economía las actividades comerciales y de servicios. Con ello, se estableció una relación de interdependencia económica entre las dos ciudades. Por su parte, la ciudad deM exicali se convirtió en el lugar de llegada y punto de salida de los migrantes, muchos de ellos indocumentados y otros legales, procedentes del interior de México hacia el Condado Imperial y otros lugares de Estados Unidos (Ortega Villa, 1993:28). 
Históricamentela ciudad deCaléxico seha caracterizado por contar con una población conformada por diferentes grupos de inmigrantes de varias nacionalidades. Desde sus inicios han predominado dos grupos de residentes: los angloamericanos y los de origen mexicano (ver cuadro 1). Los datos censales dela población dela ciudad permiten observar que desdelos años veinte ${ }^{2}$ y hasta 1960 los angloamericanos conformaban la mayoría de la población, seguidos por el grupo de mexicanos. Sin embargo, a partir de ese año la composición de la población se invirtió, de manera que el grupo que ha predominado durantelos últimos 30 años es el de origen mexicano, mismo queleha dado a la ciudad un toqueatípico, al convertirla en la ciudad fronteriza del suroeste deEstados Unidos con mayor peso relativo de población de origen mexicano (U.S. Bureau of the Census, Census of Population, 1990).

CuAdRo 1. Crecimiento y origen dela población deCaléxico, California de 1920 a 1990.

\begin{tabular}{|c|c|c|c|c|}
\hline Año & $\begin{array}{c}\text { Población } \\
\text { total }\end{array}$ & $\begin{array}{c}\text { Población de } \\
\text { origen angloamericano } \\
\%\end{array}$ & $\begin{array}{c}\text { Población deorigen } \\
\text { mexicano } \\
\%\end{array}$ & $\begin{array}{c}\text { Población de } \\
\text { otras razas } \\
\%\end{array}$ \\
\hline 1920 & 6,223 & 55.2 & 36.8 & 2.9 \\
1930 & 6,299 & 39.0 & 36.2 & 14.5 \\
1940 & 5,415 & 67.9 & 27.3 & 2.2 \\
1950 & 6,433 & 73.6 & 24.5 & 2.0 \\
1960 & 7,992 & 73.3 & 23.9 & 2.1 \\
1970 & 10,625 & 23.5 & 73.6 & 3.0 \\
1980 & 14,412 & 3.8 & 92.1 & 2.0 \\
1990 & 18,633 & 3.0 & 95.3 & 1.7 \\
\hline
\end{tabular}

Fuente: U.S. Bureau of the Census, Census of Population. 1920 a 1990.

${ }^{2}$ La población dela ciudad de Caléxico del año de 1910 no apareceen los censos de población, sólo están publicados los datos generales de la población del Condado. 
La inmigración al Valle Imperial, como se mencionó, fue alentada por la inversión decapital norteamericano y por la necesidad demano de obra, preferentementebarata, disponibley sujeta a las necesi dades estacional es dela agricultura y a los intereses del capital (Acuña, et al ., 1983:51); pero también es, en buena medida, reflejo de los acontecimientos histórico-estructural es que se han suscitado tanto en México como en Estados Unidos. Por ejemplo, el porcentaje de población de origen mexicano en 1920 y 1930 (ver cuadro 1) fue consecuencia de la revolución mexicana; sin embargo, para el año de 1940 este grupo decrece, llegando a representar sólo el 27.3\% de la población, este decremento fue el resultado de las políticas de deportación adoptadas por el gobierno estadounidense en la década de los treinta, que fueron tomadas con el propósito de abatir el desempleo generado por la crisis económica definales dela década de 1920, conocida como la crisis del '29; de hecho la población total de 1940 es inferior en números absolutos a la de 1930 y a la de 1920. Estas medidas deexpulsión fueron apoyadas por las autoridades estatales y como resultado miles detrabajadores mexicanos salieron por la fuerza o voluntariamente (Massey, et al ., 1991:55) .

Durante las siguientes décadas la inmigración de mexicanos manifestó un incremento moderado, a pesar de que eran los años en que se encontraba vigente el programa bracero, que inició en 1942 y convirtióal Vallelmperial en el principal punto dedestino. La relación dedicho programa con estazona agrícol a semanifestó en el gran centro dereclutamiento bracero dela franja fronteriza: Caléxico-M exicali, que fue uno de los lugares de braceros que reclutó más trabajadores y dio al Valle Imperial un fuerte impulso con su fuerza de trabajo (Massey, et al., 1991:189). Cabemencionar queal término del Programa Bracero, en 1964, muchos de los trabajadores (braceros) sevieron favorecidos al obtener los documentos que les permitió establecerse como residentes legales en el país, con base en las facilidades otorgadas por las leyes de inmigración que estaban vigentes en ese tiempo (Massey, et al., 1991:98).

El cambio en la composición dela población se debeen gran medida a las características económicas del Condado Imperial: en primer lugar, a los cambios en su estructura productiva, ya que si bien el sector 
agrícola sigue siendo importante ${ }^{3}$ y el sector secundario real mente no se ha desarrollado, el peso del sector terciario ha aumentado considerablemente, como consecuencia dela proliferación decomercios que abastecen a los residentes de M exicali; en segundo lugar, a su ubicación geográfica, pues ésta favorecea los norteamericanos, ya que seencuentra muy cerca deotros condados como San Diego y Riverside, que son lugares en donde tienen mayores oportunidades de relacionarsecultural y socialmentey, por último, a los inmigrantes mexicanos residentes legales les ofrece la posibilidad de no perder el contacto familiar y sociocultural con el país deorigen, dada la contigüidad con una ciudad mexicana.

\section{CARACTERÍSTICASSOCIODEMÓGRAFICASY OCUPACIONALES DE LOS INMIGRANTESMEXICANOSRESIDENTESLEGALESEN CALÉXICO}

La población objetivo del proyecto deinvestigación, sedefinió como el conjunto demexicanos residentes permanentes legales en la ciudad de Caléxico, cuya edad fuese de 18 años o más y que aún no hubieran optado por la ciudadanía estadounidense. Dela etapa delevantamiento de información se obtuvieron 407 entrevistas, de ellas el $42.5 \%$ correspondió al sexo masculino y el $57.5 \%$ al femenino.

En general, la muestra presenta a una población joven, con un promedio de edad de 43.5 años $( \pm 1.56 \text { años })^{4}$ sin diferencias

\footnotetext{
${ }^{3}$ La estructura productiva agrícola en el valle sí ha manifestado cambios. En un principio se sembraban legumbres y hortalizas, cultivos que requieren abundante mano deobra para la recolección. A partir de 1970 los cultivos se diversificaron y se empezaron a sembrar en mayor cantidad granos y forraje, que favorecieron la sustitución de fuerza de trabajo por maquinaria. La cantidad de tierra que actualmente se utiliza para cultivar sigue siendo relativamente la misma que en 1930, que era al rededor de 400,000 acres (Dowd, 1956:76), la cual ha aumentado durantelas dos últimas décadas, según el censo deagricultura de 1980 seutilizaron para cultivo 449,868 acres y en 1990 aumentó la cantidad a 463,522 acres. En estas dos décadas censalmente también se registró un aumento considerable en la introducción demaquinaria agrícola (U.S. Bureau of the Census, A gricultureCensus of Imperial County 1980-1990).

${ }^{4}$ Producto del error estándar multiplicado por 2 como aproximación del valor Z = 1.96 (cota del error de estimación).
} 
significativas entre hombres y mujeres. En conjunto, el $42 \%$ registra una edad entre los 18 y 39 años de edad (ver cuadro 2), con un predominio del grupo delos 40 a 49 años deedad (26.8\%) y una mayor participación relativa de los hombres en los grupos de 18 a 29 y de 60 y más años de edad.

CUADRo 2. Mexicanos residentes legales en Caléxico. Composición de la muestra según edad y sexo.

\begin{tabular}{|c|c|c|c|c|c|c|}
\hline \multirow[t]{2}{*}{ Grupo de edad } & \multicolumn{2}{|c|}{ Hombres } & \multicolumn{2}{|c|}{ Mujeres } & \multicolumn{2}{|c|}{ Total } \\
\hline & Abs. & $\%$ & Abs. & $\%$ & Abs. & $\%$ \\
\hline 18 a 29 & 40 & 23.2 & 42 & 17.9 & 82 & 20.2 \\
\hline 30 a 39 & 32 & 18.6 & 57 & 24.4 & 89 & 21.9 \\
\hline 40 a 49 & 39 & 22.7 & 70 & 29.9 & 109 & 26.8 \\
\hline 50 a 59 & 21 & 12.2 & 33 & 14.1 & 54 & 13.3 \\
\hline 60 y más & 40 & 23.3 & 32 & 13.7 & 72 & 17.7 \\
\hline No especificado & 1 & & & & 1 & \\
\hline Total & 173 & 100.0 & 234 & 100.0 & 407 & 100.0 \\
\hline
\end{tabular}

Fuente: Resultados del proyecto “Inmigración e integración de los mexicanos residentes legales en Caléxico, Ca.", IIs-SDSU, 1995.

Ya en 1990 el 95.6\% de la población dela ciudad deCaléxico era de origen hispano ${ }^{5}$ de la cual el $99.7 \%$ era de origen mexicano, dicho en otros términos, 95.3 decada 100 residentes deCaléxico eran mexicanos o descendientes de éstos, los cuales provienen de diferentes estados dela república mexicana (ver cuadro 3), sobre todo deaquellos estados quese encuentran en la costa del Pacífico desdeMichoacán hasta Baja California, en los quepredominan losnacidosen Baja California (46.7\%) y en el estado deSinaloa (10.3\%).

${ }^{5}$ El censo de población de Estados Unidos de 1990 identifica como población hispana a aquélla que se autoclasificó en esta categoría, que incluye a mexicanos, puertorriqueños, cubanos o de otro origen español/ hispano, independientemente dela raza (U.S. Department of Comerse, 1992). 
CuAdRo 3. Mexicanos residentes legales en Caléxico según entidad federativa de nacimiento y sexo.*

\begin{tabular}{|l|r|r|r|r|r|r|}
\hline \multirow{2}{*}{ Grupo de edad } & \multicolumn{2}{|c|}{ Hombres } & \multicolumn{2}{c|}{ Mujeres } & \multicolumn{2}{c|}{ Total } \\
\cline { 2 - 7 } & A bs. & $\%$ & A bs. & $\%$ & A bs. & $\%$ \\
\hline \multirow{3}{*}{ Baja California } & 78 & 45.2 & 112 & 47.9 & 190 & 46.7 \\
Jalisco & 18 & 10.4 & 20 & 8.5 & 38 & 9.3 \\
Michoacán & 13 & 7.5 & 10 & 4.3 & 23 & 5.7 \\
Sinaloa & 12 & 6.9 & 30 & 12.8 & 42 & 10.3 \\
Sonora & 16 & 9.2 & 16 & 6.8 & 32 & 7.9 \\
Otros estados & 36 & 20.8 & 46 & 19.7 & 82 & 20.1 \\
Total & 173 & 100.0 & 234 & 100.0 & 407 & 100.0 \\
& & & & & & \\
\hline
\end{tabular}

FuENTE: Encuesta del proyecto "Inmigración e integración de los mexicanos residentes legales en Caléxico, Ca.", IIS-SDSU, 1995.

* Los resultados de la prueba $\mathrm{c}^{2}$ no fueron significativos, por lo tanto la composición de la muestra según sexos es independiente del lugar de origen.

Otra delas características a destacar dela población objeto deestudio esla edad en quelos mexicanos emigraron a Estados Unidos, el cuadro 4 permiteadvertir diferencias en estesentido. En primer lugar, destaca la alta proporción de personas que emigraron de 0 a 19 años de edad (46.4\%) con una fuerteparticipación en estegrupo deaquellas en edad no laboral, es decir, de 0 a 15 años de edad (29.8\%).

Por otro lado, seobserva quepoco más dela mitad delosentrevistados (51.3\%) salió deM éxico entrelos 20 y 49años, deelloslamayor frecuencia relativa está en el grupo de los quetenían entre 20 y 29 años, tanto en el total como en cada una de las entidades mencionadas, esto último con excepción deBaja California, cuya mayor frecuencia relativaseubica en el primer grupo de edad, ya que el $45.7 \%$ de los migrantes bajacalifornianos lo hicieron a una edad igual o menor a 15 años.

En segundo lugar, son evidentes las diferencias en la edad de migración según el lugar de nacimiento. Así, cabe destacar que del grupo que salió de México de 1 a 15 años de edad, poco menos detres cuartas partes está compuesto por nativos deBaja California; porcentaje quedesciende conformese presenta una mayor distancia delos estados 
ubicados en la costa del Pacífico con la frontera, con excepción de la también entidad fronteriza deSonora. Esta misma tendencia seobserva en el grupo de personas que migraron entre los 16 y 19 años de edad, en el cual de nuevo Baja California registra el mayor peso relativo (56.7\%). Estos datos sugieren quela proximidad geográfica favorecela migración a una edad más temprana, al menos en el caso específico de los migrantes en esta local idad en particular.

CUADRO 4. Mexicanos residentes legales en Caléxico, según edad en que emigró y entidad federativa de nacimiento. Porcentajes.*

\begin{tabular}{|c|c|c|c|c|c|c|c|}
\hline $\begin{array}{l}\text { Edad a la } \\
\text { quemigró }\end{array}$ & B.C. & Jalisco & Mich. & Sinaloa & Sonora & $\begin{array}{c}\text { Otra } \\
\text { ent. fed. }\end{array}$ & Total \\
\hline \multicolumn{8}{|l|}{0 a 15} \\
\hline$\%$ del G.E. & 71.7 & 3.3 & 2.5 & 5.8 & 3.3 & 13.3 & \multirow[t]{2}{*}{29.8} \\
\hline $\begin{array}{l}\text { \% de la E.F } \\
16 \text { a } 19\end{array}$ & 45.7 & 10.5 & 13.0 & 17.1 & 12.5 & 19.8 & \\
\hline$\%$ del G.E. & 56.7 & 4.5 & 3.0 & 9.0 & 6.0 & 20.9 & \multirow[t]{2}{*}{16.6} \\
\hline $\begin{array}{l}\% \text { de la E.F } \\
20 \text { a } 29\end{array}$ & 20.2 & 7.9 & 8.7 & 14.6 & 12.5 & 17.3 & \\
\hline \% del G.E. & 35.5 & 15.3 & 6.5 & 12.9 & 9.7 & 20.2 & \multirow[t]{2}{*}{30.8} \\
\hline $\begin{array}{l}\% \text { de la E.F } \\
30 \text { a } 39\end{array}$ & 23.4 & 50.0 & 34.8 & 39.0 & 37.5 & 30.9 & \\
\hline$\%$ del G.E. & 23.6 & 14.5 & 12.7 & 9.1 & 9.1 & 30.9 & \multirow[t]{2}{*}{13.6} \\
\hline $\begin{array}{l}\% \text { de la E.F } \\
40 \text { a } 49\end{array}$ & 6.9 & 21.1 & 30.4 & 12.2 & 15.6 & 21.0 & \\
\hline \% del G.E. & 25.0 & 7.1 & 10.7 & 17.9 & 10.7 & 28.6 & \multirow{3}{*}{6.9} \\
\hline \% dela E.F & 3.7 & 5.3 & 13.0 & 12.2 & 9.4 & 9.9 & \\
\hline 50 y más & & & & & & & \\
\hline \% del G.E. & & 22.2 & & 22.2 & 44.4 & 11.1 & 2.2 \\
\hline \% dela E.F & & 5.3 & & 4.9 & 12.5 & 1.2 & \\
\hline Total G.E & 46.7 & 9.4 & 5.7 & 10.2 & 7.9 & 20.1 & \multirow[t]{2}{*}{100.0} \\
\hline $\begin{array}{l}\text { Total E.F. } \\
\text { Estadísticos }\end{array}$ & 100.0 & 100.0 & 100.0 & 100.0 & 100.0 & 100.0 & \\
\hline Media & 16.883 & 26.789 & 26.435 & 25.829 & 28.656 & 24.284 & 21.69 \\
\hline Error est. & .713 & 1.701 & 2.325 & 1.816 & 2.640 & 1.343 & 0.59 \\
\hline Desv. Est. & 9.77 & 10.488 & 11.15 & 11.625 & 14.933 & 12.083 & 11.94 \\
\hline Casos & 188 & 38 & 23 & 41 & 32 & 81 & 403 \\
\hline
\end{tabular}

Fuente: Encuesta del proyecto "Inmigración e integración de los mexicanos residentes legales en Caléxico, Ca.", IIS-SDSU, 1995.

* La prueba $\mathrm{c}^{2}$ para este cuadro resultó altamentesignificativa $(a<.0001)$, así como el coeficiente de correlación de Spearman $\left(r_{\mathrm{s}}=.333\right.$ con a <.0001). G.E. =del grupo de edad. E.F. = de la entidad federativa. 
En la partefinal del cuadro 4 seincluyen las medias de edad en que migraron los mexicanos residentes en Caléxico según la entidad federativa de nacimiento. Al comparar la media los nativos de Baja California con las demás entidades, seobtuvieron resultados al tamente significativos ( $a$ <.001) en todos los casos; sin embargo, las pruebas no fueron significativas al comparar entre sí al resto de los estados, es decir, salvo el caso de Baja California, los promedios de edad de migración no son estadísticamentediferentes. Finalmente, cabedestacar la existencia de una leve pero significativa asociación entre edad de emigración y lugar de origen ( $r s=.33, a<00001$ ).

\section{CONDICIÓN DE OCUPACIÓN EN LOS PAÍSES DE ORIGEN Y DESTINOY MOVILIDAD LABORAL}

En cuanto a la condición de ocupación de los inmigrantes mexicanos residentes legal es en Caléxico, del total delas personas entrevistadas, la mitad no había realizado un trabajo previo en México (ver cuadro 5); sin embargo, este porcentajeestá afectado, en buena medida, por el hecho de que casi el 30\% de los migrantes no tenía edad para trabajar cuando salió de su país (ver cuadro 4).

En esteaspecto, cabe destacar que sól o el 4.3\% dela muestra reportó nunca haber trabajado en Estados Unidos, aunque al momento del levantamiento sólo el $46.9 \%$ contaba con empleo; esto último posiblemente esté asociado, por un lado, al fuerte peso de la población femenina en la muestra y, por el otro, al carácter estacional deal gunas actividades deCaléxico, principalmenteala agricultura y el comercio, esteúltimo muy sensiblea los cambios en la economía dela ciudad de Mexicali, Baja Cal ifornia, tanto a la paridad cambiaria peso-dólar como a la temporada en que disminuye el consumo de los mexical enses en aquella ciudad, particularmente en verano.

Por otro lado, también Ilama la atención que del total de personas quesí habían laborado en México, el 91.1\% también ha trabajado en el país de destino, una situación similar se observa en el grupo de inmigrantes que no trabajó en México aunque en menor medida, ya que de éstos el $80.4 \%$ al menos una vez ha laborado en los Estados Unidos. 
CUADRO 5. Condición deocupación delos mexicanos residentes legales en Caléxico.

\begin{tabular}{|c|c|c|c|c|c|c|}
\hline \multirow[t]{2}{*}{$\begin{array}{l}\text { Condición de } \\
\text { ocupación }\end{array}$} & \multicolumn{2}{|c|}{$\begin{array}{c}\text { Trabajó } \\
\text { en México }\end{array}$} & \multicolumn{2}{|c|}{$\begin{array}{c}\text { Ha trabajado } \\
\text { en E.U. }\end{array}$} & \multicolumn{2}{|c|}{$\begin{array}{c}\text { Trabaja } \\
\text { actualmente }\end{array}$} \\
\hline & abs. & $\%$ & abs. & $\%$ & abs. & $\%$ \\
\hline Total & 407 & 100.0 & 407 & 100.0 & 407 & 100.0 \\
\hline Sí (encabezado de columna) & 203 & 49.9 & 349 & 85.7 & 191 & 46.9 \\
\hline No (encabezado de columna) & 204 & 50.1 & 58 & 4.3 & 216 & 53.1 \\
\hline Sí trabajaron en México & & & 203 & 100.0 & 203 & 100.0 \\
\hline Sí (encabezado de columna) & & & 185 & 91.1 & 101 & 49.8 \\
\hline No (encabezado de columna) & & & 18 & 8.9 & 102 & 50.2 \\
\hline No trabajaron en México & & & 204 & 100.0 & 204 & 100.0 \\
\hline Sí (encabezado de columna) & & & 164 & 80.4 & 90 & 44.1 \\
\hline No (encabezado de columna) & & & 40 & 19.6 & 114 & 55.9 \\
\hline
\end{tabular}

FuentE: Encuesta del proyecto “Inmigración e integración de los mexicanos residentes legales en Caléxico, Ca.", IIs-SDSU, 1995.

A dicional mente, es importante destacar la menor participación de las mujeres en el mercado laboral en relación con los hombres, ello a pesar desu mayor peso relativo en la composición dela muestra. Así, del total de personas que sí disponían de antecedentes laborales en México (203casos) el porcentajecorrespondientedelas mujeres resultó del $45.3 \%$ (inferior al $54.7 \%$ delos varones), porcentajecasi igual (45\%) al total de ocupados al momento del levantamiento (191 casos). Por otro lado, casi el 70\% delos migrantes quenunca trabajaron en México (204 casos) son mujeres, así como también 52 delas 58 personas (89.7\%) que nunca han trabajado en Estados Unidos y el $68.5 \%$ de los no ocupados al momento del levantamiento (216 casos).

Una primera aproximación a los cambios ocupacionales de los migrantes mexicanosen Caléxico es identificar la estructuraocupacional de la última actividad realizada en México y la primera en Estados Unidos (ver cuadro 6); sin embargo, cabe destacar que los totales del 
cuadro 6 para ambos grupos no coinciden porque el número de personas con antecedentes laborales en México es menor al delos que seincorporaron al mercado detrabajo en el país dedestino, es decir, el total dequienes sereporta el primer trabajo en Estad os Unidos incluye a aquellas personas que migraron en edad no laboral e iniciaron actividades en ese país, más adelante (cuadro 7) se presenta el seguimiento delos casos particulares delos migrantes quehan trabajado en ambos países.

CUADRO 6. Último trabajo en México y primero en los Estados Unidos de los mexicanos residentes legales en Caléxico, $\mathrm{Ca}$.

\begin{tabular}{|c|c|c|c|c|}
\hline \multirow[t]{2}{*}{ Ocupación } & \multicolumn{2}{|c|}{ Último trabajo en México } & \multicolumn{2}{|c|}{ Primer trabajo en E.U. } \\
\hline & Abs. & $\%$ & Abs. & $\%$ \\
\hline Agricultura & 47 & 23.1 & 193 & 55.3 \\
\hline Construcción & 17 & 8.4 & 34 & 9.7 \\
\hline Comercio & 66 & 32.5 & 63 & 18.1 \\
\hline Educación & 4 & 2.0 & 16 & 4.6 \\
\hline Servicios comunal & 17 & 8.4 & 17 & 4.9 \\
\hline Servs. finan. y ban & nca & & 10 & 2.9 \\
\hline Transporte & & & 1 & 0.3 \\
\hline Otro & & & 12 & 3.4 \\
\hline No especificado & 52 & 25.6 & 3 & 0.8 \\
\hline Total & 203 & 100.0 & 349 & 100.0 \\
\hline
\end{tabular}

FUENTE: Encuesta del proyecto "Inmigración e integración de los mexicanos residentes legales en Caléxico, Ca.”, UABC-SDSU, 1995

Un primer aspecto a destacar es la importancia que adquiere la actividad agrícola en el país receptor, ya que para un poco más de la mitad de los inmigrantes mexicanos entrevistados (55.3\%) esta actividad fue su primer fuente de trabajo, porcentaje que es más del doble al observado como la última ocupación en México (23.2\%). También llama la atención el hecho dequeel sector dela construcción no registra cambios relativos fuertes, pues del $8.4 \%$ en M éxico pasa al 
9.7\% en Estados Unidos. Por su parte, el peso relativo delos ocupados en el comercio y en los servicios comunales disminuyea casi la mitad, ello se puede deber, por un lado, al hecho de que la mayor oferta de trabajo es de carácter agrícola (intensiva en fuerza de trabajo) y, por el otro, a que otros sectores de actividad requieren de personal con cierta calificación, particularmenteel dominio del idioma inglés, con excepción dela construcción.

En el cuadro 5 se observa que del total de la muestra, sólo 185 inmigrantes contaban con antecedentes laboral es en ambos países, y es este grupo el que sirve como indicador para observar la movilidad laboral desdeuna perspectiva sectorial einternacional. En estesentido, un primer aspecto a destacar en el cuadro 7 es la confirmación de la importancia dela agricultura como primer fuentedetrabajo delos inmigrantes mexicanos, ya que 6.2 de cada 10 personas con antecedentes laborales en México tuvieron su primer empleo en las actividades agrícolas, dicho en otros términos, por cada inmigrante dedicado a la agricultura en México, en Caléxico lo hicieron 2.6.

Estemayor peso de los trabajadores agrícolas en Caléxico seefectuó de la transferencia de aquellos que en México se dedicaban principalmente al comercio - que se redujo casi a la mitad y refleja una movilidad horizontal (sectorial) descendente-, y a las actividades no especificadas. Deigual forma, Ilamala atención queel total depersonas dedicadas a la construcción se mantuvo igual en ambos lugares.

Por otro lado, al revisar la distribución delosmigrantes por actividad en los lugares de origen y destino se observa que 66 de los 185 trabajadores (35.7\%) no registraron movilidad ocupacional al guna. Así, destaca que, del total de personas que trabajaron en la agricultura en México, casi la totalidad (43 de 45) continuaron en esa actividad en Estados Unidos, 5 de los 17 dedicados a la construcción y 13 de los 61 ocupados en el comercio.

Al revisar los cambios específicos de cada actividad, seobserva que hubo transferencias de trabajadores de los sectores terciario y secundario en favor del primario, es decir, depersonas queen México trabajaban en la construcción (8 de 17), en el comercio (31 de 61) y en actividades no especificadas ( 27 de 45), inserción al mercado laboral queestá determinada por la estructura económica local. Por otro lado, 
si bien en términos absolutos no hubo cambios en el número de empleados ocupados en la construcción, el cuadro 7 muestra que la pérdida de los migrantes dedicados a esta actividad (muchos de los cuales pasaron a la agricultura), fue compensada, en su mayoría, por los que en México se dedicaban a actividades comerciales, lo que de nuevo muestra una movilidad sectorial descendente.

De igual forma, destaca el hecho de que 21 de los 61 (34.4\%) empleados en actividades comerciales en México se mantuvieron en actividades terciarias en Estados Unidos. Finalmente, si bien el peso relativo delos inmigrantes queen México sededicaban a los servicios comunales no es de los más importantes (7.0\%), éste se reduce aún más en Estados Unidos (4.3\%) y más de la mitad de ellos (7 de 13) permanece en actividades terciarias. Los inmigrantes que en México se dedicaban a ambas actividades (comercio y servicios comunales), son losquepresentan una mayor diversificación ocupacional en el lugar dedestino.

M OVILIDAD LABORAL SEGÚN TIEM PO DE RESIDEN CIA, DOM INIO DEL IDIOMA Y NIVEL EDUCATIVO

El hecho dequela agricultura es la actividad que dio empleo a más de la mitad delos inmigrantes no es deextrañar, ya quehistóricamenteel sector primario ha sido el queha ofertado empleos al a fuerza detrabajo extranjera, esto debido a las características de esta región del sur de California y al reducido tamaño desu población; sin embargo, ello no significa que una vez asentada esta población en el lugar de destino no busque mejores opciones ocupacionales en otros sectores de actividad.

El cuadro 8 fue elaborado bajo el supuesto de que los inmigrantes, conformeaumentaran su tiempo de residencia en el lugar de destino, acumularían experiencia y mayor especial ización en su trabajo, lo que se traduciría en cambios en el sector de ocupación, esto es, del sector primario al secundario o terciario - los cuales, en general, presentan mejores condiciones laborales, tanto porque son trabajos menos extenuantes que el agrícola como porque no se llevan a cabo a la intemperie - a la par que las vacantes por ellos generadas fueran 
CUADRO 7. Movilidad laboral de los inmigrantes mexicanos con antecedentes laborales en México y en Estados Unidos.

\begin{tabular}{|c|c|c|c|c|c|c|c|c|c|}
\hline \multirow{2}{*}{$\begin{array}{l}\text { Último trabajo } \\
\text { en México }\end{array}$} & \multicolumn{7}{|c|}{ Primer trabajo desempeñado en Estados Unidos } & \multirow{2}{*}{$\begin{array}{l}\text { Total en } \\
\text { México }\end{array}$} & \multirow{2}{*}{$\begin{array}{c}\% \text { del } \\
\text { gran tota }\end{array}$} \\
\hline & Agricultura & Comercio & Construcción & Educación & S. Comunitario & Banco & No especificado & & \\
\hline Agricultura & 43 & & 1 & & 1 & & & 45 & $24.3 \%$ \\
\hline De la act. en Méx. & $95.6 \%$ & & $2.2 \%$ & & $2.2 \%$ & & & $100.0 \%$ & \\
\hline De la act. en E.U. & $37.4 \%$ & & $5.9 \%$ & & $12.5 \%$ & & & & \\
\hline Comercio & 31 & 13 & 7 & 4 & 4 & & 2 & 61 & $33.0 \%$ \\
\hline De la act. en Méx. & $50.8 \%$ & $21.3 \%$ & $11.5 \%$ & $6.6 \%$ & $6.6 \%$ & & $3.3 \%$ & $100.0 \%$ & \\
\hline De la act. en E.U. & $27.0 \%$ & $41.9 \%$ & $41.2 \%$ & $80.0 \%$ & $50.0 \%$ & & $28.6 \%$ & & \\
\hline Construción & 8 & 3 & 5 & & 1 & & & 17 & $9.2 \%$ \\
\hline De la act. en Méx. & $47.1 \%$ & $17.6 \%$ & $29.4 \%$ & & $5.9 \%$ & & & $100.0 \%$ & \\
\hline De la act. en E.U. & $7.0 \%$ & $9.7 \%$ & $29.4 \%$ & & $12.5 \%$ & & & & \\
\hline Educación & 1 & 2 & & & 1 & & & 4 & $2.2 \%$ \\
\hline De la act. en Méx. & $25.0 \%$ & $50.0 \%$ & & & $25.0 \%$ & & & $100.0 \%$ & \\
\hline De la act. en E.U. & $0.9 \%$ & $6.5 \%$ & & & $12.5 \%$ & & & & \\
\hline Servicio comunitario & 5 & 4 & & 1 & 1 & 1 & 1 & 13 & $7.0 \%$ \\
\hline De la act. en Méx. & $38.5 \%$ & $30.8 \%$ & & $7.7 \%$ & $7.7 \%$ & $7.7 \%$ & $7.7 \%$ & $100.0 \%$ & \\
\hline De la act. en E.U. & $4.3 \%$ & $12.9 \%$ & & $20.0 \%$ & $12.5 \%$ & $50.0 \%$ & $14.3 \%$ & & \\
\hline No especificado & 27 & 9 & 4 & & & 1 & 4 & 45 & $24.3 \%$ \\
\hline De la act. en Méx. & $60.0 \%$ & $20.0 \%$ & $8.9 \%$ & & & $2.2 \%$ & $8.9 \%$ & $100.0 \%$ & \\
\hline De la act. en E.U. & $23.5 \%$ & $29.0 \%$ & $23.5 \%$ & & & $50.0 \%$ & $57.1 \%$ & & \\
\hline Total & 115 & 31 & 17 & 5 & 8 & 2 & 7 & 185 & $100.0 \%$ \\
\hline De la act. en E.U. & $100.0 \%$ & $100.0 \%$ & $100.0 \%$ & $100.0 \%$ & $100.0 \%$ & $100.0 \%$ & $100.0 \%$ & & \\
\hline$\%$ del gran total & $62.2 \%$ & $16.8 \%$ & $9.2 \%$ & $2.7 \%$ & $4.3 \%$ & $1.1 \%$ & $3.8 \%$ & $100.0 \%$ & \\
\hline
\end{tabular}

FUENTE: Encuesta del proyecto "Inmigración e integración de los mexicanos residentes legales en Caléxico, Ca." UABC-SDSU, 1995. 
cubiertas por los recién inmigrados; sin embargo, la información recopilada no permitió establecer una dependencia estadísticamente significativa entre sector de actividad y los años de residencia en Caléxico, a pesar de que los mexicanos residentes legales se ocupan mayoritariamenteen actividades terciarias en una proporción superior al doble de las primarias.

CUADRO 8. Sector de actividad actual y años de residencia en Estados Unidos. Porcentajes.

\begin{tabular}{|c|c|c|c|c|c|c|c|}
\hline \multirow{2}{*}{$\begin{array}{l}\text { Sector de } \\
\text { Actividad }\end{array}$} & \multicolumn{7}{|c|}{ Años de residencia en Estados Unidos } \\
\hline & 0 a 5 & 6 a 10 & 11 a 15 & 16 a 20 & 21 a 25 & 26 y más & Total \\
\hline Primario & & & & & & & 26.3 \\
\hline$\%$ sector & 28.0 & 16.0 & 8.0 & 22.0 & 12.0 & 14.0 & 100.0 \\
\hline$\%$ grupo edad & 36.8 & 17.8 & 16.0 & 32.4 & 33.3 & 23.3 & \\
\hline Secundario & & & & & & & 5.3 \\
\hline$\%$ sector & 10.0 & 30.0 & 10.0 & 20.0 & & 30.0 & 100.0 \\
\hline$\%$ grupo edad & 2.6 & 6.7 & 4.0 & 5.9 & & 10.0 & \\
\hline Terciario & & & & & & & 54.7 \\
\hline$\%$ sector & 15.4 & 23.1 & 17.3 & 16.3 & 10.6 & 17.3 & 100.0 \\
\hline$\%$ grupo edad & 42.1 & 53.3 & 72.0 & 50.0 & 61.1 & 60.0 & \\
\hline No especificado & & & & & & & 13.7 \\
\hline$\%$ sector & 26.9 & 38.5 & 7.7 & 15.4 & 3.8 & 7.7 & 100.0 \\
\hline$\%$ grupo edad & 18.4 & 22.2 & 8.0 & 11.8 & 5.6 & 6.7 & \\
\hline Del grupo & 100.0 & 100.0 & 100.0 & 100.0 & 100.0 & 100.0 & \\
\hline Total & 20.0 & 23.7 & 13.2 & 17.9 & 9.5 & 15.8 & 100.0 \\
\hline
\end{tabular}

FuENTE: Encuesta del proyecto "Inmigración e integración de los mexicanos residentes legales en Caléxico, Ca.”, UABC-SDSU, 1995.

Esta disminución dela importancia del sector primario en el empleo actual delos mexicanos residentes legales puedeobedecer al hecho de quela mayor partedel trabajo demandado por el sector primario dela región estésiendo cubierto por mexicanos transmigrantes (commuters), 
quienes poseen documentos para trabajar legalmente en Estados Unidos pero residen en Mexicali, mientrasquelosmexicanos residentes legales en la ciudad de Caléxico se dedican a actividades terciarias.

Otro indicador que permite abordar el estudio de la movilidad laboral delosinmigrantesessin duda el dominio del idioma oficial del lugar de destino (inglés), ya que ello puede ser un medio para tener acceso a trabajos menos intensivos en el uso de la fuerza de trabajo o con mejores condiciones laborales, es decir, una mejor inserción y/ o mayor movilidad entresectoresy/ u ocupaciones. El cuadro 9 muestra las ocupaciones y el nivel de dominio del inglés de los mexicanos que laboraban al momento del levantamiento de información.

En general, la información del cuadro 9 indica proporciones de al rededor del $20 \%$ en cada una de las tres clasificaciones más altas del dominio del inglés, es decir, 6 decada 10 inmigrantes mexicanos hablan inglés entre regular y muy bien, el resto se distribuye de manera desigual entre las clasificaciones más bajas. Así, el $16.3 \%$ de los trabajadores habla poco inglés, el $14.7 \%$ no habla ni entiendeel idioma y el $8.4 \%$ restante sólo lo entiende. Esto significa que casi una cuarta parte de los trabajadores (23.1\%) no habla inglés.

Desdeel punto de vista dela ocupación, se puedeobservar quelos trabajadores dedicados a aquellas labores que requieren de mayor cal ificación seconcentran en losniveles más altos dedominio del inglés, tal es el caso delos técnicos, oficinistasy profesionistas. Por otro lado, y de manera inversa, se puede observar que los trabajadores que desempeñan laboresno cal ificadas seubican en las categorías más bajas de la variable, tal es el caso de los trabajadores domésticos.

También Ilama la atención la presencia deocupaciones en las queel dominio del inglés pareceno ser muy relevante, ya queen el las existen empleados en todas las clasificaciones de la variable. Así, destacan los trabajadores por su cuenta, distribuidos equitativamenteentre las tres categorías altas y las tres bajas; por su parte, los empleados deservicios y los vendedores se concentran en las tres categorías al tas, mientras quelos trabajadores agrícol as y los operadores de máquinas tienden a ser mayoría en las tres clasificaciones más bajas, ya quemás dela mitad de los trabajadores agrícolas (55.1\%) se ubican en las dos categorías más bajas, es decir, no hablan inglés. Esto puede deberse no al hecho 
Cuadro 9. Última ocupación y dominio del idioma inglés. Porcentajes.*

\begin{tabular}{|c|c|c|c|c|c|c|c|}
\hline \multirow{2}{*}{$\begin{array}{l}\text { Última } \\
\text { Ocupación }\end{array}$} & \multicolumn{7}{|c|}{ Nivel de dominio del idioma inglés } \\
\hline & $\begin{array}{l}\text { Muy } \\
\text { bien }\end{array}$ & Bien & Regular & Poco & $\begin{array}{l}\text { Entiende, } \\
\text { no habla }\end{array}$ & $\begin{array}{c}\text { No habla } \\
\text { ni entiende }\end{array}$ & Total \\
\hline \multicolumn{7}{|l|}{ Trab. Agrícola } & 25.8 \\
\hline \% dela ocup. & 8.2 & 12.2 & 10.2 & 14.3 & 18.4 & 36.7 & 100.0 \\
\hline$\%$ niv. idioma & 10.0 & 16.2 & 13.2 & 22.6 & 56.3 & 64.3 & \\
\hline \multicolumn{7}{|l|}{ Técnico } & 1.1 \\
\hline \% dela ocup. & 50.0 & 50.0 & & & & & 100.0 \\
\hline$\%$ niv. idioma & 2.5 & 2.7 & & & & & \\
\hline \multicolumn{7}{|l|}{ Oficinista } & 13.7 \\
\hline \% dela ocup. & 30.8 & 34.6 & 30.8 & 3.8 & & & 100.0 \\
\hline$\%$ niv. idioma & 20.0 & 24.3 & 21.1 & 3.2 & & & \\
\hline \multicolumn{7}{|l|}{ Operador demáq. } & 4.7 \\
\hline$\%$ dela ocup. & 22.2 & 11.1 & 11.1 & 22.2 & 22.2 & 11.1 & 100.0 \\
\hline$\%$ niv. idioma & 5.0 & 2.7 & 2.6 & 6.5 & 12.5 & 3.6 & \\
\hline \multicolumn{7}{|l|}{ Vendedor } & 14.7 \\
\hline \% dela ocup. & 14.3 & 17.9 & 32.1 & 21.4 & 7.1 & 7.1 & 100.0 \\
\hline \% niv. idioma & 10.0 & 13.5 & 23.7 & 19.4 & 12.5 & 7.1 & \\
\hline \multicolumn{7}{|c|}{ Emp. Servs. } & 12.6 \\
\hline$\%$ dela ocup. & 29.2 & 16.7 & 20.8 & 16.7 & 4.2 & 12.5 & 100.0 \\
\hline$\%$ niv. idioma & 17.5 & 10.8 & 13.2 & 12.9 & 6.3 & 10.7 & \\
\hline \multicolumn{7}{|c|}{ Op. Transp. } & 1.6 \\
\hline$\%$ de la ocup. & & & 33.3 & 66.7 & & & 100.0 \\
\hline$\%$ niv. idioma & & & 2.6 & 6.5 & & & \\
\hline \multicolumn{5}{|l|}{ Trabajador dom. } & & 3.2 & \\
\hline \% dela ocup. & & & 33.3 & 33.3 & 16.7 & 16.7 & 100.0 \\
\hline \% niv. idioma & & & 5.3 & 6.5 & 6.3 & 3.6 & \\
\hline \multicolumn{5}{|c|}{ Trab. por su cuenta } & & 5.3 & \\
\hline \% dela ocup. & .20 .0 & 20.0 & 10.0 & 20.0 & 10.0 & 20.0 & 100.0 \\
\hline \% niv. idioma & 5.0 & 5.4 & 2.6 & 6.5 & 6.3 & 7.1 & \\
\hline \multicolumn{7}{|l|}{ Profesionista } & 3.7 \\
\hline \% dela ocup. & 71.4 & 14.3 & 14.3 & & & & 100.0 \\
\hline$\%$ niv. idioma & 12.5 & 2.7 & 2.6 & & & & \\
\hline \multicolumn{7}{|c|}{ Otro } & 13.7 \\
\hline$\%$ de la ocup. & 26.9 & 30.8 & 19.2 & 19.2 & & 3.8 & 100.0 \\
\hline$\%$ niv. idioma & 17.5 & 21.6 & 13.2 & 16.1 & & 3.6 & \\
\hline Nivel idioma & 100.0 & 100.0 & 100.0 & 100.0 & 100.0 & 100.0 & \\
\hline Total & 21.1 & 19.5 & 20.0 & 16.3 & 8.4 & 14.7 & 100.0 \\
\hline
\end{tabular}

FUENTE: Encuesta del proyecto "Inmigración e integración de los mexicanos residentes legales en Caléxico, Ca.", UABC-SDSU, 1995.

$*$ Prueba $c^{2}$ significativa $(a=.0013), \mathrm{V}$ de Cramer $=.30$ ( $\left.\mathrm{a}=.0013\right)$. 
de que las actividades agrícolas no requieren del conocimiento del idioma para realizar dichas labores, puesto que no se orientan a la atención depersonas, como es el caso deotros sectores, particularmente el decomercio y servicios. Finalmente, los datos del cuadro 9 permiten advertir queel total delos trabajadores detransporte presentan niveles intermedios del dominio del inglés (clasificaciones de poco y regular).

En síntesis, se puede considerar queel tipo de empleo dependeen cierta medida del dominio del inglés, así lo confirman las pruebas estadísticas realizadas (ver nota al piedel cuadro 9), ya que, en general, los trabajadores ocupados en actividades demayor calificación y menos intensivas muestran tener mayor conocimiento del idioma que los trabajadores en la situación opuesta, como los trabajadores agrícolas, domésticos y operadores de máquinas, quienes tienen menor conocimiento del idioma.

La escolaridad de los inmigrantes puede ser otro indicador de importancia en su inserción en el mercado laboral. En el cuadro 10, se presentan los estudios real izados por este grupo deinmigrantes en su lugar de origen y en Estados Unidos según edad a la que emigró. Así, desdeel punto devista dela escolaridad obtenida en México, seobserva queen el total predominan los migrantes quecursaron al gún grado de educación básica en M éxico (261 de los 407 o 64.1\%) seguidos por los que no estudiaron (14.7\%) mientras que la minoría corresponde a los migrantes quellegaron al nivel superior (2.9\%). Ello habla deuna baja escolaridad adquirida en el lugar de origen, ya que 7.9 de cada 10 migrantes o no estudiaron o sólo cursaron educación básica (primaria y secundaria) en México; sin embargo, hay que matizar la afirmación anterior, ya quela escol aridad está asociada a la edad. A sí, cabe destacar el hecho de que, del total de migrantes que no hicieron estudios en México, un poco más dela mitad (31 de 57 o 54.4\%) emigró a una edad no escolar (menos de 5 años), que, junto con los que están en dicha situación del siguientegrupo deedad (6a 15) suman dosterceras partes delos migrantes que no cursaron estudio alguno en M éxico.

El mismo cuadro 10 permite advertir que los grupos deedad de 16 a 25 años, además deser el más grande(39.8\%), es el que presenta una mayor diversificación en los estudios realizados en México y concentra a la mitad de los migrantes con estudios a nivel superior ( 6 de 12), al 
$69 \%$ de los que cursaron estudios técnicos o comerciales (20 de 29) y al $76.2 \%$ de los que llegaron a media superior (32 de 42). La diversidad en la escolaridad de estegrupo era de esperarse, por las edades de que setrata, aunqueello también seobserva en los mexicanos queemigraron a una edad entre 26 y 35 años; no obstante, destaca la baja escolaridad lograda por los dos últimos grupos de edad, ya que más de la mitad del grupo queemigró entre 46y 55 años y todos los quelo hicieron de 55 y más, cuando mucho llegaron hasta la secundaria. Sin embargo, cabe destacar el hecho de que haber real izado estudios en México no es una variable que influya en la inserción de los migrantes en el mercado laboral, al menos eso indican los resultados estadísticos. ${ }^{6}$

Al observar el cuadro 10 desde el punto de vista de los estudios realizados en el país de destino, destaca, en primer lugar, el peso de los migrantes que no han cursado estudios en Estados Unidos (176 de 407 o el $43.2 \%$ ), seguido por el grupo delos quesólo estudiaron inglés (31.9\%). Por otro lado, al revisar los grupos deedad, destaca el peso de los que emigraron en edad escolar ( $a$ una edad menor o igual a 25 años) en el total de los migrantes que cursaron educación formal (98 de 101 o el 97\%), pero también concentran a más dela mitad (94 delos 176 o el $53.4 \%$ ) de los migrantes que no realizaron estudio al guno en Estados Unidos.

Los grupos demexicanos queemigraron entre 26 y 45 años destacan por su interés en aprender inglés, ya que en el primer grupo (26 a 35 años) aproximadamenteuno de cada tres (36.4\%) lo hizo, queaunados a los que continuaron su educación formal, representan el $40.9 \%$ (27 de 66) desu grupo, mientras que en el grupo que emigró entre 36 y 45 el 30.8\% estudió inglés en lugar de destino. Esteinterés por aprender la lengua inglesa, y en general por estudiar, disminuye conforme la edad deemigración es mayor.

${ }^{6}$ Se corrió una regresión logística para identificar la relación entre haber o no estudiado en México (variable dependiente) con la ocupación actual (variable independiente) y los resultados no fueron significativos. 
CuAdRO 10. Estudios realizados en México y en Estados Unidos según edad de emigración.

\begin{tabular}{|c|c|c|c|c|c|c|c|c|}
\hline \multirow{2}{*}{$\begin{array}{l}\text { Grupo } \\
\text { deedad }\end{array}$} & \multirow{2}{*}{$\begin{array}{l}\text { Estudios } \\
\text { en E.U. }\end{array}$} & \multicolumn{6}{|c|}{ Estudios realizados en México* } & \multirow[t]{2}{*}{ Total } \\
\hline & & Ninguno & $\begin{array}{l}\text { Educ. } \\
\text { básic }\end{array}$ & $\begin{array}{l}\text { Med. } \\
\text { sup. }\end{array}$ & $\begin{array}{l}\text { Com. } \\
\text { o téc. }\end{array}$ & Sup. & $\begin{array}{l}\text { No } \\
\text { esp. }\end{array}$ & \\
\hline \multirow[t]{4}{*}{ Total } & Ninguno & 17 & 137 & 12 & 5 & 5 & 0 & 176 \\
\hline & Inglés & 9 & 74 & 22 & 20 & 3 & 2 & 130 \\
\hline & Ed. formal & 31 & 50 & 8 & 4 & 4 & 4 & 101 \\
\hline & Total & 57 & 261 & 42 & 29 & 12 & 6 & 407 \\
\hline \multirow[t]{4}{*}{0 a 5 años } & Ninguno & 3 & 1 & & & & & 4 \\
\hline & Inglés & 5 & & & & & & 5 \\
\hline & Ed. formal & 23 & 1 & & & & 2 & 26 \\
\hline & Total & 31 & 2 & & & & & 35 \\
\hline \multirow[t]{4}{*}{6 a 15 años } & Ninguno & 1 & 19 & & & & & 20 \\
\hline & Inglés & & 17 & 2 & 1 & & & 20 \\
\hline & Ed. formal & 6 & 37 & & & & 2 & 45 \\
\hline & Total & 7 & 73 & 2 & 1 & & & 85 \\
\hline \multirow[t]{4}{*}{16 a 25 años } & Ninguno & 2 & 55 & 9 & 3 & 1 & & 70 \\
\hline & Inglés & 3 & 32 & 15 & 13 & 1 & 1 & 65 \\
\hline & Ed. formal & 1 & 10 & 8 & 4 & 4 & & 27 \\
\hline & Total & 6 & 97 & 32 & 20 & 6 & 1 & 162 \\
\hline \multirow[t]{4}{*}{26 a 35 años } & Ninguno & 4 & 31 & 2 & & 2 & & 39 \\
\hline & Inglés & 1 & 17 & 2 & 3 & 1 & & 24 \\
\hline & Ed. formal & 1 & 2 & & & & & 3 \\
\hline & Total & 6 & 50 & 4 & 3 & 3 & & 66 \\
\hline \multirow[t]{4}{*}{36 a 45 años } & Ninguno & 4 & 21 & & 2 & & & 27 \\
\hline & Inglés & & 6 & 2 & 3 & 1 & & 12 \\
\hline & Ed. formal & & & & & & & 0 \\
\hline & Total & 4 & 27 & 2 & 5 & 1 & & 39 \\
\hline \multirow[t]{4}{*}{46 a 55 años } & Ninguno & 2 & 7 & 1 & & 2 & & 12 \\
\hline & Inglés & & & 1 & & & & 1 \\
\hline & Ed. formal & & & & & & & 0 \\
\hline & Total & 2 & 7 & 2 & 0 & 2 & & 13 \\
\hline \multirow[t]{3}{*}{56 y más } & Ninguno & 1 & 2 & & & & & 3 \\
\hline & $\begin{array}{l}\text { Inglés } \\
\text { Ed formal }\end{array}$ & & & & & & & \\
\hline & Total & 1 & 2 & & & & & 3 \\
\hline \multirow[t]{4}{*}{ No especif. } & Ninguno & & 1 & & & & & 1 \\
\hline & Inglés & & 2 & & & & 1 & 2 \\
\hline & Ed. formal & & & & & & & \\
\hline & Total & & 3 & & & & 1 & 4 \\
\hline
\end{tabular}

FuentE: Encuesta del proyecto "Inmigración e integración de los mexicanos residentes legales en Caléxico, Ca.", UABC-SDSU, 1995.

* Terminados o inconclusos. 
CUADRO 11. Estudios realizados en México y en Estados Unidos según ocupación.

\begin{tabular}{|c|c|c|c|c|c|c|c|c|}
\hline \multirow[t]{2}{*}{ Ocupación } & \multirow{2}{*}{$\begin{array}{c}\text { Estudios } \\
\text { en E.U. }\end{array}$} & \multicolumn{6}{|c|}{ Estudios en México* } & \multirow[t]{2}{*}{ Total } \\
\hline & & Ninguno & $\begin{array}{l}\text { Educ. } \\
\text { básic }\end{array}$ & $\begin{array}{l}\text { Med. } \\
\text { sup. }\end{array}$ & $\begin{array}{l}\text { Com. } \\
\text { o téc. }\end{array}$ & Sup. & $\begin{array}{l}\text { No } \\
\text { esp. }\end{array}$ & \\
\hline \multirow[t]{4}{*}{ Total } & Ninguno & 5 & 52 & 7 & 2 & 3 & 0 & 69 \\
\hline & Inglés & 7 & 29 & 13 & 8 & 2 & 1 & 60 \\
\hline & Ed formal & 21 & 28 & 6 & 2 & 3 & 2 & 62 \\
\hline & Total & 33 & 109 & 26 & 12 & 8 & 3 & 191 \\
\hline \multirow[t]{4}{*}{ T.Agrícolas } & Ninguno & 1 & 32 & 2 & 1 & 2 & & 38 \\
\hline & Inglés & & 5 & 1 & & & 1 & 7 \\
\hline & Ed formal & 2 & 2 & & & 1 & & 5 \\
\hline & Total & 3 & 39 & 3 & 1 & 3 & 1 & 50 \\
\hline \multirow[t]{2}{*}{ Técnicos } & Ed formal & 1 & 1 & & & & & 2 \\
\hline & Total & 1 & 1 & & & & & 2 \\
\hline \multirow[t]{4}{*}{ Oficinistas } & Ninguno & 1 & 1 & & & & & 2 \\
\hline & Inglés & 2 & 5 & 1 & 4 & 1 & & 13 \\
\hline & Ed formal & 4 & 6 & 1 & & & & 11 \\
\hline & Total & 7 & 12 & 2 & 4 & 1 & & 26 \\
\hline \multirow[t]{4}{*}{ Op. de maq } & Ninguno & & 2 & 1 & & & & 3 \\
\hline & Inglés & 1 & 2 & 1 & & & & 4 \\
\hline & Ed formal & & 2 & & & & & 2 \\
\hline & Total & 1 & 6 & 2 & & & & 9 \\
\hline \multirow[t]{4}{*}{ Vendedor } & Ninguno & 1 & 5 & 1 & 1 & 1 & & 9 \\
\hline & Inglés & & 3 & 3 & 2 & & & 8 \\
\hline & Ed formal & 5 & 4 & & 1 & & 1 & 11 \\
\hline & Total & 6 & 12 & 4 & 4 & 1 & 1 & 28 \\
\hline \multirow[t]{4}{*}{ Emp deservs. } & Ninguno & & 6 & 2 & & & & 8 \\
\hline & Inglés & & 3 & 2 & 1 & & & 6 \\
\hline & Ed formal & 2 & 7 & 1 & & & & 10 \\
\hline & Total & 2 & 16 & 5 & 1 & & & 24 \\
\hline \multirow[t]{3}{*}{ Op. transporte } & e Ninguno & & 2 & & & & & 2 \\
\hline & Inglés & & 1 & & & & & 1 \\
\hline & Total & & 3 & & & & & 3 \\
\hline \multirow{3}{*}{ Trab.domést. } & Ninguno & & 1 & & & & & 1 \\
\hline & Inglés & 2 & 2 & 1 & & & & 5 \\
\hline & Total & 2 & 3 & 1 & & & & 6 \\
\hline \multirow{4}{*}{$\begin{array}{l}\text { Trab. por su } \\
\text { cuenta }\end{array}$} & Ninguno & 2 & 1 & 1 & & & & 4 \\
\hline & Inglés & & 2 & 1 & & & & 3 \\
\hline & Ed formal & 1 & 1 & & 1 & & & 3 \\
\hline & Total & 3 & 4 & 2 & 1 & & & 10 \\
\hline \multirow[t]{2}{*}{ Profesionistas } & Ed formal & 3 & 1 & 1 & & 1 & 1 & 7 \\
\hline & Total & 3 & 1 & 1 & & 1 & 1 & 7 \\
\hline \multirow[t]{4}{*}{ Otra ocup } & Ninguno & & 2 & & & & & 2 \\
\hline & Inglés & 2 & 6 & 3 & 1 & 1 & & 13 \\
\hline & Ed formal & 3 & 4 & 3 & & 1 & & 11 \\
\hline & Total & 5 & 12 & 6 & 1 & 2 & & 26 \\
\hline
\end{tabular}

FuENTE: Encuesta del proyecto "Inmigración e integración de los mexicanos residentes legales en Caléxico, Ca.", UABC-SDSU, 1995.

* Terminados o inconclusos. 
El cuadro 11 muestra los estudios realizados, tanto en México como en Estados Unidos, por los mexicanos migrantes que laboraban al momento del levantamiento según sus ocupaciones. Esto debido a que las pruebas estadísticas real izadas para identificar la asociación entre la ocupación actual y dominio del inglés resultaron altamente significativas, esto es, el nivel deconocimiento del inglés está asociado, aunque no fuertemente, a la ocupación actual (ver pie del cuadro 9), y a que se encontró que la probabilidad de trabajar en Estados Unidos está asociada al hecho de haber o no estudiado en ese país. ${ }^{7}$ En dicho cuadro se destaca el peso delosmexicanos quehan cursado al gún tipo deestudiosen EstadosUnidos, ya quesi sesuman los quehan recibido instrucción formal con los que han estudiado inglés tenemos que el 63.9\% (122 de 191) de los quetrabajan han estudiado en el país receptor. Deellos, los que han recibido instrucción formal se concentran en los oficinistas, los vendedores (11 de 62 o 17.7\% en ambos casos), en los empleados de servicios y los profesionistas, todas ellas actividades terciarias menos agotadoras que el trabajo agrícola.

A nivel de las ocupaciones, destaca el hecho de que los migrantes que se dedican al ejercicio de una profesión o que trabajan como técnicos son los únicos grupos ocupacional es que en su totalidad han recibido instrucción formal en Estados Unidos; además esta categoría (educación formal) es la más frecuente entre los vendedores y los empleados deservicios y la segunda en importancia entrelos oficinistas.

En oposición, destaca el hecho de que trabajadores agrícolas concentran al $55.1 \%$ del total de los migrantes que no han cursado estudio al guno en Estados Unidos (38 de 69), que representan el 76\% de todos los trabajadores agrícolas; de igual forma, de las diferentes ocupaciones estegrupo es el queen términos relativos presenta lamenor proporción de migrantes que estudiaron inglés (7 de 50 o 14\%). Otras ocupaciones que también presentan un bajo perfil educativo son los operadores de transporte y los trabajadores domésticos, aunque la mayoría de estos últimos han estudiado inglés en el país receptor.

${ }^{7}$ Los resultados de la regresión logística muestran una débil pero significativa relación ( $p<.001$ ). La condición deocupación (trabaja o no) seutilizó como variable dependientey como independientela ocupación. 
Por otro lado, si bien los estudios realizados en México no están asociados al hecho de trabajar en Estados Unidos, es evidente la baja escolaridad de los migrantes que trabajaban al momento del levantamiento, situación que, como se dijo está influida por la edad en que emigraron (ver cuadro 10). Aun así, es evidente la movilidad descendente de al gunos migrantes que cursaron educación superior, ya que tres de los ocho se dedican a actividades agrícolas, otro es vendedor y sólo uno labora como profesionista; sin embargo, esteúltimo también cursó educación formal en Estados Unidos.

Así, es claro que, independientemente de los estudios que los migrantes real izaron en M éxico, la inserción en el mercado laboral y el tipo deactividad que desempeñan en el país receptor dependededos situaciones: en primer lugar, dela oferta detrabajo en el lugar dedestino $y$, en segundo lugar, de los estudios que los migrantes realicen en EstadosUnidos, particularmente del inglés.

\section{CONSIDERACIONESFINALES}

Este trabajo se planteó como propósito el describir a un grupo de mexicanos residentes legales en una ciudad fronteriza de Estados Unidos: Caléxico, Ca., así como su inserción y movilidad laboral. Como resultado una característica a destacar de este grupo es que los inmigrantes mexicanos proceden mayoritariamentedecinco entidades federativas mexicanas ubicadas en la costa del Pacífico que forman parte de una corriente migratoria que parte del estado de Michoacán hacia el norte, delascuales Baja Cal ifornia aporta casi la mitad deellos. Por otro lado, también sobresale el hecho de que los nacidos en Baja California registran un promedio de edad al momento de emigrar significativamente menor a las medias registradas por los nativos de las demás entidades mexicanas. Estas dos particularidades de los nacidos en Baja Cal ifornia entre los mexicanos residentes en Cal éxico -elevado peso relativo en el conjunto y menor edad al momento de emigrar - se pueden deber a que la cercanía con Estados Unidos les permite, por un lado, tener mayor acceso alainformación delasociedad receptora (incluso contacto) y a los trámites de inmigración y, por el otro, al funcionamiento ágil, por la proximidad, delas redes familiares 
que representan una vía para tramitar la residencia legal en ese país; mientras que los inmigrantes provenientes de otras entidades tienen que enfrentarse al problema de la distancia, que implica mayores tiempos en el envío de documentos y gastos detraslado, primero para llegar a la frontera mexicana y posteriormente para entrar a Estados Unidos.

En el trabajo se propuso también observar la actividad laboral de losinmigrantes como indicador dela movilidad laboral. En estesentido, al comparar la última actividad realizada en México con la primera en Estados Unidos, se observa una movilidad descendente, ya que para la mayoría de los inmigrantes, su primer empleo en ese país fue en actividades intensivas como la agricultura (55.3\%), y la construcción (9.7\%), frente a un perfil laboral en México que era más diversificado, con fuerte concentración en actividades comerciales, agrícolas y no especificadas.

Por otro lado, al analizar el sector de actividad de los inmigrantes que se encontraban ocupados al momento del levantamiento de la información, se observaron cambios respecto del primer trabajo realizado en Estados Unidos. Así, el peso delas actividades primarias, deocupar a más del $50 \%$ de los trabajadores descendió al $26 \%$, mientras que el sector terciario concentra actualmente a más de la mitad de la fuerza de trabajo mexicana residente legal en Caléxico. Una posible explicación de este hecho es que el trabajo demandado por el sector primario es realizado en buena parte por los trabajadores transmigrantes (commuters), es decir, mexicanos residentes de la ciudad de Mexicali, B.C. (México), quetienen permiso para trabajar en Estados Unidos y cotidianamente cruzan la frontera para trabajar en el Valle Imperial.

Esto sugiereuna diferenciación delos mexicanos en relación con la ocupación en el país de destino, ya que si bien su primer fuente de trabajo en Estados Unidos es principalmente agrícola, una vez asentadosallí, y adquirido cierto conocimiento del idioma, la estructura ocupacional cambia y seterciariza, sólo permanecen en las actividades agrícolas quienes tienen un pobre dominio del inglés o quienes no logran cursar estudios más allá del nivel básico. Las vacantes generadas por estecambio en el sector deactividad son cubiertas por otro grupo 
demexicanos con permiso para residir y/ o trabajar en Estados Unidos, pero quienes han optado por continuar como residentes permanentes del lado mexicano de la frontera.

También cabedestacar queel tiempo deresidencia en el país receptor no es condicionante para que se lleve a cabo la movilidad sectorial o laboral, como tampoco lo es el hecho de haber estudiado en México; sin embargo, sí influye en el tipo de actividad desempeñada tanto el conocimiento de la lengua inglesa como el hecho de haber cursado educación formal en Estados Unidosy, sobretodo, las necesidades del mercado de trabajo en el lugar de destino.

En síntesis, la información permite afirmar que los inmigrantes mexicanos residentes legales en Caléxico al momento de Ilegada presentan una movilidad descendente y, en la medida en que logran cursar estudios en Estados Unidos presentan una movilidad laboral horizontal, ya que pasan fundamental mente de las actividades primarias hacialas terciarias, en las queel dominio idioma inglés tiene un papel importante. Además, queda de manifiesto la fuerterelación entre las dos ciudades fronterizas de Mexicali y Caléxico, la primera como puerta de salida de mano de obra requerida por la segunda y principal mercado de sus bienes ofertados, mientras que Caléxico representa la posibilidad de mejorar las condiciones de vida de los mexicanos que allí laboran, ya sea que residan o no en ella.

Final mente, reconocemos que hay al gunas otras variables de interés que permitirían profundizar el estudio de los migrantes residentes legales en Caléxico pero queaquí no seabordan, ya queello implicaría extender demasiado el documento, tales como: las posi bles diferencias entre los migrantes debidas a los estudios real izad os tanto en M éxico como en Estados Unidos según la entidad federativa de procedencia y todos aquell os aspectos asociados al género, a saber: las diferencias en escolaridad, lugar de procedencia, condición y tipo deocupación, entre otras. 


\section{BIBLIOGRAFÍA}

Acuña, Guadalupe Beatriz, et al. (1983). El trabajador agrícola transmigrante dela frontera M unicipio deM exicali-Condado Imperial. Reporteterminal, IIS-UABC, Mexicali, B. C.

Alegría, Tito. (1992). Desarrollo urbano en la frontera M éxico-Estados U nidos. U na interpretación y algunos resultados. Consejo Nacional para la Cultura y las Artes, México, D. F.

Clark, W. A. V. (1986). H uman M igration. Sage Publications, Beverly Hills.

Comisión sobre el Futuro de las Relaciones M éxico-Estados Unidos. (1988). El desafío de la interdependencia: M éxico-Estados U nidos. F.C.E. México.

CONAPO-CONEPO (1986). Encuesta demográfica de Baja California. CONAPO-CONEPO, Mexicali, B.C..

Cuamea Velázquez, Felipe(1991). “M ovilidad dela fuerza detrabajo, aspectos territoriales, ocupacionales y sectoriales. A nálisis de Caso en San Felipe, Baja California". Tesis deMaestría, Facultad deA rquitectura, $\cup A B C$, Mexicali, B. C.

Dowd, M. J. (1956). "History of Imperial Irrigation Distric and the Development of Imperial Valley". Publicado por Imperial Irrigation Distric, Community and Special Services, El Centro, California. [Distrito]

Esparza Lozano, Froylán (1983). “El desarrollo económico”, Panorama histórico de Baja California. Universidad Autónoma de Baja California. Mexicali, Baja California, pp. 587-600.

Estrella Valenzuela, Gabriel (1982). “El origen dela región delos valles de Mexicali e Imperial, desde la perspectiva de las relaciones sociales". Cuadernos deCiencias Sociales, núm. 1, IIS-UABC, Mexicali, B. C.

Gaudemar, Jean-Paul de (1976). M ovilidad del trabajo y acumulación de capital. Ediciones Era, México, D. F.

Gómez Quiñones, Juan (1979). “La importancia de la exportación de capital eimportación demano deobra”. H istoria y Sociedad, núm. 20, M éxico, D. F. 
INEGI. 1991. XI Censo general de población y vivienda, 1990. Resultados definitivos. Tabulados básicos. Baja California. INEGI, Ags.

Massey, Douglas, et al. (1991). Los ausentes. Consejo Nacional para la Cultura y las A rtes-Ed. Alianza, México, D. F.

Ortega Villa, Guadalupe(1993). “Local ización residencial en la ciudad de Mexicali: una aplicación del Modelo de Alonso", Tesis de Maestría (mimeo), Instituto de Investigaciones Sociales, UABC, Mexicali, B.C.

U. S. Bureau of the Census. Census of Population. 1900, 1910, 1920, 1930, 1940, 1950, 1960, 1970, 1980, 1990. Washington, D. C.

A griculture Census for Imperial County, 1980, 1990. Washington, D. C.

U.S. Department of Commerce (1992). Statistical A bstract of the U nited States 1992. U.S. Department of Commerce. Economics and Statistics Administration. Bureau of the Census. Washington, D.C.

Verduzco Igartúa, Gustavo (1990). “La migración urbana a Estados Unidos: un caso del occidente de México". Estudios Sociológicos. El Colegio de México, Vol. VIII, núm. 22, enero-abril. 